crustaceans, the Remipedia, and numerous new species have been found, many of which are living fossils with particular adaptations to their dark underwater life. A major scientific expedition is being planned for 1987 to take up this biological and geological challenge and to fully document the fauna. The book ends with an important conservation message, pointing out the narrow path trod between scientific discovery and the opening up of the caves to abuse and destruction: 'If we play with the caves, if we treat them as toys, they will die'. The Lucayan Cavern on Grand Bahama, the world's largest known underwater cave system, has now been made a national park administered by the Bahamas National Trust; Rob Palmer's book makes a clear case for treating such an exciting and fragile ecosystem with great care.

Sue Wells, Conservation Monitoring Centre, IUCN

\section{Birds in Scotland \\ Valerie M. Thom \\ T. \& A.D. Poyser Ltd, 1986, 382 pp, drawings, maps, photographs, £24}

This book constitutes an up-to-date review of the status of the birds, together with impressive chapters on distribution, habitat, conservation and protection. Authoratively and attractively written, this is a mine of information and has been produced to the usual exacting standards one now expects from Poyser's. Pity about some of the drawings though: the tree creeper, some finches, yellow-browed and barred warblers, for example, leave much to be desired.

Tim Parmenter, British Museum (Natural History)

\section{Life of the Woodpecker}

Alexander Skutch

Croom Helm, Beckenham, Kent, UK, 1986, 136 pp, £45

Despite their popularity, there are few major works on woodpeckers. This is not a taxonomic monograph, and hardly covers their systematics, evolution and identification, but Alexander Skutch has presented a very readable account of their life history, well applying his long ex- perience, particularly in Central America. It is beautifully illustrated, with paintings by Dana Gardner of nearly one-third of the 200 species. A chapter on Woodpeckers and Man discusses the problems that woodpeckers can make for man and that man can make for woodpeckers in modern forest clearance or management methods, and the inadequacies of most reafforestation. Many species are already threatenedpredictably, since the status of many woodpeckers is reflected in the 'abundance of trees in all stages of their natural cycle of germination, growth, flowering, fruiting and decay'.

The book is one of the modern genre of lavish (and hence expensive) productions.

\section{A.M. Hutson}

\section{Also received}

The Ecology of Woodland Rodents: Bank

Voles and Woodmice. The Proceedings of a

Symposium held at the Zoological Society of

London on 23 and 24 November 1984.

Edited by J.R. Flowerdew, J. Gurnell and J.H.W.

Gipps

Oxford University Press, 1986, £42.00

This collection of 14 papers from 16 contributors covers behaviour, communication, reproduction, food, energetics, genetics, predators and parasites, movement, the dynamics and modelling of populations, and community ecology.

\section{The Biosphere Catalogue.}

Editor-in-Chief, Tango Parrish Snyder

Synergetic Press, 1985, £9.95 PB

Designed to develop a conceptual understanding for the 'student' of the biosphere, this catalogue touches upon 24 areas of study, from biomes to microbes, from cultures to travel. Contributors include Norman Myers, author of The Sinking Ark and General Editor of The Gaia Atlas of Planetary Management, Alwyn Gentry and Ghillean Prance.

\section{Arctic Dreams: Imagination and Desire in a Northern Landscape}

Barry Lopez

Macmillan London, 1986, £14.95 HB

A celebration of the Arctic landscape, its wild animals and its people. 